Journal of Sensor Science and Technology

Vol. 21, No. 1 (2012) pp. 34-38

http://dx.doi.org/10.5369/JSST.2012.21.1.34

pISSN 1225-5475/eISSN 2093-7563

\title{
$\mathrm{BeCu}$ 금속박판을 이용한 테스트 소켓 제작
}

\author{
김봉환+
}

\section{Fabrication of Test Socket from BeCu Metal Sheet}

\author{
Bonghwan $\mathrm{Kim}^{+}$
}

\begin{abstract}
We have developed a cost effective test socket for ball grid array(BGA) integrated circuit(IC) packages using BeCu metal sheet as a test probe. The $\mathrm{BeCu}$ furnishes the best combination of electrical conductivity and corrosion resistance. The probe of the test socket was designed with a $\mathrm{BeCu}$ cantilever. The cantilever was designed with a length of $450 \mu \mathrm{m}$, a width of $200 \mu \mathrm{m}$, a thickness of $10 \mu \mathrm{m}$, and a pitch of $650 \mu \mathrm{m}$ for $11 \times 11 \mathrm{BGA}$. The fabrication of the test socket used techniques such as through-silicon-via filling, bonding silicon wafer and BeCu metal sheet with dry film resist(DFR). The test socket is applicable for BGA IC chip.
\end{abstract}

Keywords : $\mathrm{BeCu}$, Test Socket, Probe

\section{1. 서 론}

테스트(test)는 전자부품이나 전자소자의 전기적 특성을 검사를 할 수 있는 장비인 테스터(tester)를 이용하여 제품의 양품과 불량 을 판별하는 일체의 행위를 말한다. 그 중에서 IC 테스트 소켓(test socket)은 메모리와 비메모리 반도체 IC패키지의 전기적인 양- 불 량 여부를 체크하기 위한 검사장비이다. IC 패키지(package)는 쓰 루홀(through hole) 패기지와 표면실장형 패키지 기술을 많이 사 용한다. 쓰루홀 패키지에는 dual inline package(DIP)가 있고[1, 2] 표면실장형 패키지는 small outline package(SOP)[3], thin SOP(TSOP)[3], quad flat package(QFP)[4], ball grid $\operatorname{array}(\mathrm{BGA})[5-11]$ 등이 있다. 이러한 다양한 패키지중에 area array package 인 BGA 패키지는 이차원적 평면에 격자 형식으로 분포된 솔더볼을 통하여 printed circuit board(PCB)에 전기적으 로 연결할 수 있는 패키지로, 단위 패키지 면적당 매우 높은 I/O 수 를 가질 수 있고, 솔더볼을 사용하므로 짧은 접속거리에 의해 낮은 인턱턴스와 커패시턴스를 가져서 고성능소자 패키지에 적합하다 (Fig. 1참조). BGA 패키지의 종류에는 플라스틱 BGA(P-BGA)[5], 세라믹 BGA(C-BGA)[6], tape BGA[7] 등으로 분류할 수 있다. P$\mathrm{BGA}$ 는 가격이 저렴해서 마이크로프로세서에 많이 사용되고 C-

대구가톨릭대학교 전자공학과(Department of Electronics Engineering, Catholic University of Daegu)

${ }^{+}$Corresponding author: bhkim@cu.ac.kr

(Received: Oct. 13, 2011, Accepted : Nov. 27, 2011)
$\mathrm{BGA}$ 는 열적 안정성이 요구되는 경우에 많이 사용하며, T-BGA는 플립칩 기술을 이용한 것으로서, 다른 두 BGA 보다 미세피치화가 가능하고 소형화, 경량화에 유리한 특징이 있다.
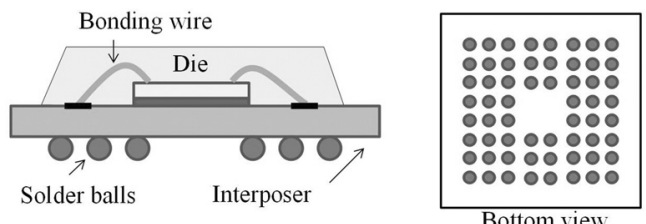

Fig. 1. Concept of ball grid array package.

BGA IC package 테스트용으로 현재 가장 많이 사용되고 있는 테스트 소켓은 포고핀(pogo-pin) 형태의 테스트 소켓이다[1-5]. 포 고핀 타입의 테스트 소켓은 테스터로부터 발생된 전기적 신호가 로 드보드(load board)를 통해 소켓핀으로 전달되고, 곧 디바이스의 각 핀으로 전해져서 테스트를 수행하는 장치이다. 포고핀 형태의 테 스트 소켓은 내구성이 좋고 큰 접촉힘을 가지고 있지만, 수작업으로 인한 조립의 번거러움과 비싼 제작단가, 큰 접촉힘으로 인한 소자 손상, 포고핀의 길이로 인한 고속동작소자 측정에는 어려움이 있다. 이런 단점을 해결하기 위해 프로브 카드에 많이 사용되는 기술인 외 팔보 형태의 프로브로 제작된 테스트 소켓이 소개되었다[12]. 외팔 보 형태의 프로브는 포고핀 형태와 달리 반도체 공정을 이용한 일괄 공정이 가능하여 미세피치에 유리하며, 대량생산이 가능하여 저가 의 테스트 소켓을 만들 수 있다. 하지만 여전히 테스트 소켓의 검침 
을 담당하는 부분이 실리콘이어서 제작공정이 다소 복잡하여, 저가형 의 테스트 소켓을 만드는데 한계가 있다. 저비용으로 제작 가능한 테 스트 소켓을 만들기 위해서는 제작공정을 단순화하고 저가형이면서 도 기존의 테스트 소켓과 동일한 성능을 내는 재료를 프로브로 사용 하여야 한다. 따라서 충분한 탄성을 가지고 마모와 내부식성이 강한 물질이면서도 손쉽게 제작할 수 있어 상업적으로 쉽게 구할 수 있는 물질을 사용하여야 한다. 이런 요구조건에 부합하는 프로브 물질로 berylliyum copper(BeCu)를 들 수 있다[12, 13]. 본 논문에서는 포고 핀 방식의 테스트 소켓의 단점을 보완하고, 대체할 수 있는 외팔보 형 태의 테스트 소켓을 $\mathrm{BeCu}$ 금속박판(metal sheet)을 이용하여 미세 피치에 대응 가능한 테스트 소켓을 제작하는 방법을 제안하였다.

\section{2. 설계 및 제작}

\section{1 설계}

본 연구에서는 포고핀 방식의 테스트 소켓이 큰 점촉힘을 가져야 하는 문제점을 보완하고 공정비용을 절감하기 위해, Fig. 2와 같이 $\mathrm{BeCu}$ 금속박판을 이용하여 외팔보 형태의 테스트 소켓을 제안하였 다. $\mathrm{BeCu}$ 는 상용으로 널리 사용되는 재료로서 전도성, 내부식성, 기 계적인 강도와 전기적인 특성이 상대적으로 좋은 장점을 가지고 있 다. $\mathrm{BeCu}$ 를 이용한 BGA IC package용 테스트 소켓을 제작하기 위 해서 외팔보 프로브의 길이와 두께, 폭은 각각 $425 \mu \mathrm{m}, 10 \mu \mathrm{m}, 200$ $\mu \mathrm{m}$ 로 설계하였다[14]. 테스트 소켓의 외팔보의 설계는 일반적인 형 태의 외팔보 모델을 사용하여 계산과 시뮬레이션을 통하여 설계하였 다[14, 15]. 저가형의 테스트 소켓을 구현하기 위하여 $\mathrm{BeCu}$ 를 프로 브 물질로 사용하고, 제작공정을 단순화 하기 위하여 $\mathrm{BeCu}$ 금속박 판을 구리도금 시드층으로 사용하여 전기도금하며, 미세피치를 구현 하기 위하여 솔드볼의 크기와 유사하게 프로브의 너비를 설계하였 다. 현재 BGA IC 패키지의 피치는 $1 \mathrm{~mm}$ 에서 $300 \mu \mathrm{m}$ 정도까지 이 지만 향후 더 줄어들 수 있다. 반도체 일괄공정을 이용하여 제안된 기술을 적용하면 $300 \mu \mathrm{m}$ 이하의 피치에도 충분히 대응 가능한 테스 트 소켓을 제작할 수 있다고 판단된다. 본 설계에서는 상용으로 사용 가능한 테스트 소켓을 만들기 위하여 상용되는 BGA IC를 이용하였 다. 측정에 사용 된 BGA IC 패키지는 볼 수가 121 개, 피치가 650 $\mu \mathrm{m}$, 볼 직경 $300 \mu \mathrm{m}$, 높이 $200 \mu \mathrm{m}$ 을 가지고 있다[15, 16].

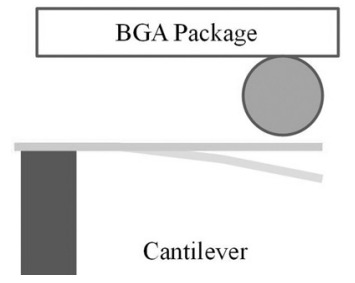

Fig. 2. Concept of test socket for BGA IC package.

\section{2 제작}

먼저 6 인치 $675 \mu \mathrm{m}$ 두께의 웨이퍼를 폴리싱 하여 $400 \mu \mathrm{m}$ 두께 로 가공하였으며, 양면이 경면인 웨이퍼로 만들었다. 그 후 initial cleaning을 한 후, 실리콘 관통을 위하여 MA6 aligner를 이용하여 photoresist(PR) AZ 4620를 노광하여 패터닝을 하는 사진식각공 정(photolithography)을 진행하였다(Fig. 3(a)). Through silicon via(TSV) 기술을 사용하기 위해 후면에 via hole 패턴을 하였다. 다음으로 웨이퍼 관통을 위하여 deep reactive ion etching(Deep $\mathrm{RIE}$ ) 장비를 이용하였다(Fig. 3(b)). 테스트 소켓의 배선이 지나가 는 via hole의 절연을 위하여 관통된 웨이퍼에 열산화막을 올렸다 (Fig. 3(c)). 열산화막은 furnace를 이용하여 $1000{ }^{\circ} \mathrm{C}$ 에서 $1 \mu \mathrm{m}$ 두 께로 증착하였다. 다음으로 $\mathrm{BeCu}$ 금속박판을 웨이퍼에 부착하기 위하여 dry film resist(DFR)를 실리콘에 라미네이팅 후 패터닝을 진행하였다. 또한 via hole 내부에 도금진행이 가능하도록 via hole 과 같은 크기의 패턴을 만들었다. 일반적으로 전기도금 공정 을 위해서는 시드층이 필요하다. 특히 TSV형태의 전극을 위해서는 via hole 측면에 전기도금이 가능한 $\mathrm{Ti} / \mathrm{Cu}$ 나 $\mathrm{Ti} / \mathrm{Au}$ 같은 시드층 을 사용한다. 반면에, 제작공정을 단순화하기 위하여 제안된 테스트 소켓의 제작공정상의 특징은, $\mathrm{BeCu}$ 금속박판과 시드층을 이용하여 vial hole을 채우지 않고, $\mathrm{BeCu}$ 박판을 그대로 시드층으로 이용하 여 bottom-up도금이 되게 하는 기술이다. 따라서 via hole을 빈틈 없이 잘 채우기 위해서는 $\mathrm{BeCu}$ 박판과 실리콘 웨이퍼와의 접합이 대단히 중요하다. $\mathrm{BeCu}$ 박판과 실리콘 웨이퍼간의 완벽한 접합을 위하여 진공 라미네이팅 장비를 이용하였다. 접합은 $100{ }^{\circ} \mathrm{C}, 0.5$ $\mathrm{MPa}$ 에서 1분간 실시하였다[15](Fig. 3(d)).

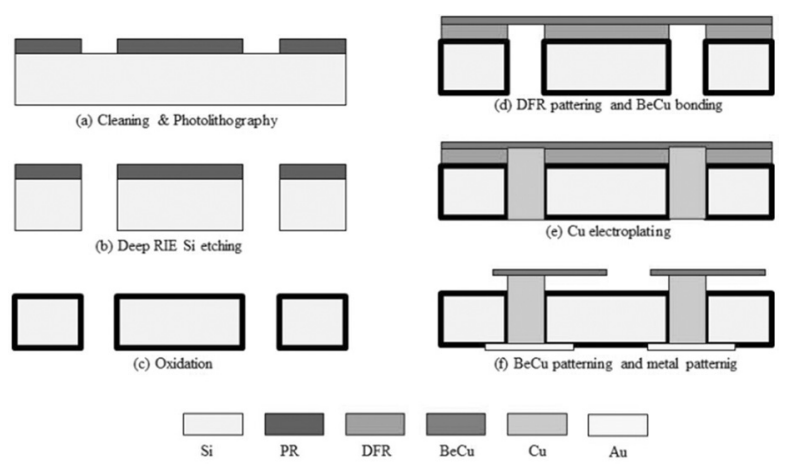

Fig. 3. Process flow of test socket.

다음으로 TSV형태의 관통 전극을 형성하기 위해 $\mathrm{Cu}$ 도금공정을 진행하였다(Table 1 참조)(Fig. $3(\mathrm{e})) . \mathrm{Cu}$ 도금 공정은 실온에서 펄스 파를 사용하여 양극에 $\mathrm{Cu}$ 이온을 만들 수 있는 볼을 망안에 넣어서 장착하고 음극에 실리콘 웨이퍼를 고정시켜 시간을 변화시키며 도금 을 진행하였다. Via hole 안이 균일하게 차게 하기 위하여 도금 속도 를 아주 느리게 하였으며, 실험에 사용된 도금 시간은 50 시간 정도였 
다. Table 1에서와 같이 도금공정이 장시간 진행되기 때문에 실리콘 웨이퍼의 위치에 따라 도금 두께가 다른 현상이 발생하였다. 이 현상 을 개선하기 위하여 via hole 후면에 패터닝한 DFR 이용하여 과도금 (overplating)을 진행한 후 DFR 위의 과도금된 $\mathrm{Cu}$ 를 chemical mechanical polishing(CMP)공정으로 균일하게 만들었다.

Table 1. Cu bath electroplating condition

\begin{tabular}{cc}
\hline \multicolumn{3}{c}{ Basic Bath } \\
\hline $\mathrm{CuSO}_{4} 5 \mathrm{H}_{2} \mathrm{O}$ & $160 \mathrm{~g} / \mathrm{L}$ \\
$\mathrm{H}_{2} \mathrm{SO}_{4}$ & $80 \mathrm{~g} / \mathrm{L}$ \\
Chloride & $50 \mathrm{mg} / \mathrm{L}$ \\
\hline \multicolumn{1}{c}{ Pulse Electroplating Conditions } \\
\hline Cathode & Silicon wafer \\
Anode & Phosphorous containing \\
& copper anode \\
Temperature & $25{ }^{\circ} \mathrm{C}$ \\
Peak Current density & $50 \mathrm{~mA} / \mathrm{cm}^{2}$ \\
Average Current density & $10 \mathrm{~mA} / \mathrm{cm}^{2}$ \\
Electroplating time & $50 \mathrm{hours}$ \\
\hline \hline
\end{tabular}

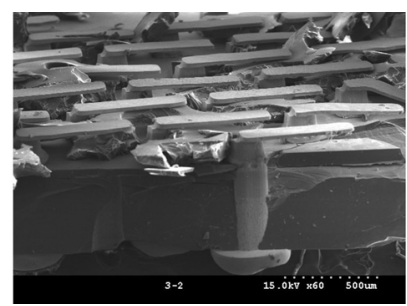

(a)

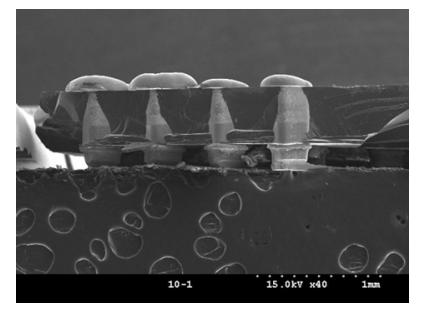

(b)

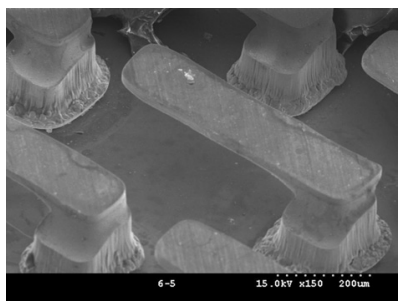

(c)

Fig. 4. Fabricated test socket. (a) Front side via hole $\mathrm{Cu}$ electroplating, (b) backside via hole $\mathrm{Cu}$ electroplating, and (c) fabricated cantilever probe.
다음으로 외팔보 프로브를 만들기 위해 DFR 전용 striper를 사 용해 DFR을 제거하였다. 그런 다음 후면 금속선(metal line) 형성 을 위하여 $\mathrm{Au}$ 도금을 하고, 전면에 외팔보 형태의 프로브를 패터닝 한 후 $\mathrm{BeCu}$ 식각용액을 사용하여 테스트 소켓을 완성하였다. 완성 된 외팔보 형태의 테스트 소켓은 Fig. 4에서 볼 수 있다. Fig. 4(a) 와 4(b)에서와 같이 TSV가 $\mathrm{Cu}$ 로 완전히 도금되어 있음을 알 수 있 다. 도금 후 $\mathrm{CMP}$ 가 진행되기 전의 $\mathrm{SEM}$ 사진이다. Fig. 4(c)는 $\mathrm{DFR}$ 제거 후의 외팔보 프로브의 모습이다.

\section{3. 결과 및 고찰}

전자소자의 특성을 평가하기 위하여, 일반적으로 기계적인 특성 인 접촉힘과 전기적인 특성인 접촉저항을 측정한다. 따라서, 제작된 외팔보 형태의 테스트 소켓의 성능을 평가하기 위하여 접촉힘과 접 촉저항을 측정하였다.

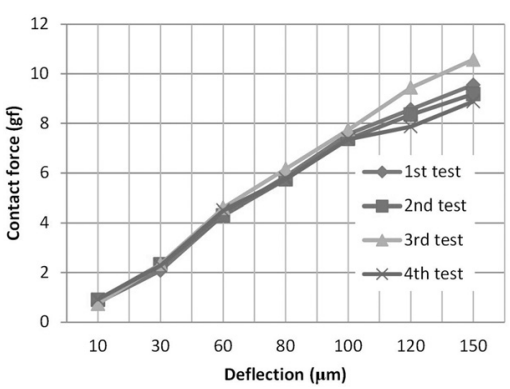

Fig. 5. Concept force as a function of deflection.

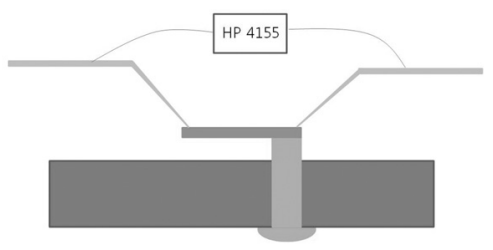

(a)

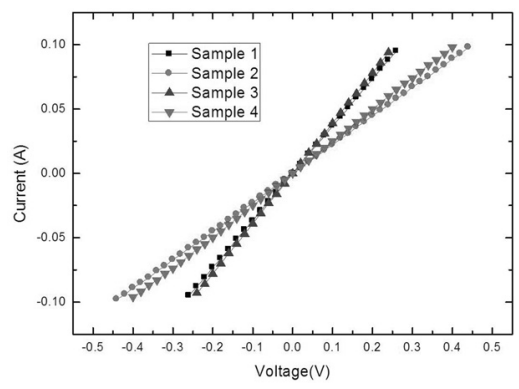

(b)

Fig. 6. Contact resistance by Kelvin method. (a) Concept of measurement and (b) graph of current vs. sweep voltage. 
접촉힘 측정을 위하여 자체적으로 제작한 측정장비를 사용하였 다. 먼저 고정된 plate위에 측정할 테스트 소켓을 올린 후 외팔보의 가장자리 부분을 로드셀이 장착된 프로브가 접촉하여 힘을 출력하 게 된다. 측정은 $30 \mathrm{gf}$ 까지 측정 가능한 로드셀을 사용하였다. Fig. 5는 테스트 소켓 프로브의 끝부분을 누르는 접촉힘과, 그에 따 른 변위의 관계를 보여주고 있다. 그림에서와 같이 접촉힘과 변위는 선형적인 관계임을 알 수 있다.

측정된 접촉힘은 $100 \mu \mathrm{m}$ 의 변위에 $8 \mathrm{gf}$ 이하의 접촉힘을 보이고 있다. 테스트 소켓 프로브 저항은 Kelvin저항측정법을 이용하여 측 정하였다[17]. 측정방법은 Fig. 6 처럼 $\mathrm{a}$ 와 $\mathrm{b}$ 사이의 저항을 측정했으 며, 프로브의 저항은 2.05 옴에서 4.48 옴 정도로 측정되었다.

\section{5. 결론}

본 연구에서는 기존 포고핀 형태의 테스트 소켓이 가진 문제점인 수작업과 고비용 제조방식을 보완하기 위하여 저비용의 $\mathrm{BeCu}$ 시트 를 이용한 외팔보 형태의 테스트 소켓을 개발하였다. 제안 된 테스 트 소켓은 공정이 단순하고, 일괄 공정에 의해 비용 절감의 효과가 크다. 또한 접촉힘이 줄어들어 솔더 볼의 마모현상을 줄일 수 있으 며, TSV를 구리로 도금하였기 때문에 짧은 도선길이로 인하여 고 속동작소자 측정에 유리하다. 따라서 BGA 패키지 테스트에 실적용 가능한 테스트 소켓이 될 수 있을 것이다.

\section{감사의 글}

이 논문은 2011년도 대구가톨릭대학교 교내연구비 지원에 의한 것임.

\section{REFERENCES}

[1] Jongwoo Park, D.G. Harlow, and H.F. Nied, "Growth kinetics of interfacial damage: epoxy coating on a generic dual inline package", IEEE Transactions on Components and Packaging Technologies, vol. 24, Issue 3, pp. 482-492, 2001.

[2] H. Hardisty and J Abboud, "Thermal analysis of a dual-in-line package using the finite-element method" IEE Proceedings, Part I - Solid-State and Electron Devices (ISSN 0143-7100), vol. 134, pt. I, no. 1, pp. 23-31, Feb. 1987.

[3] A. Emerick, J. Ellerson, J. McCreary, R. Noreika, C. Woychik, and P. Viswanadham, "Enhancement of
TSOP solder joint reliability using encapsulation", Proceedings. 43rd Electronic Components and Technology Conference, pp. 187-192, 1993.

[4] S. Sasaki and T. Kishimoto, "High-pin-count quad flat package with thin-film termination resistors", Proceedings of 1993 Japan International Electronic Manufacturing Technology Symposium, pp. 125-128, 1993.

[5] C.Y. Chung, "A novel package electrical characterization process-application on plastic BGA packages", Proceedings of the 1st Electronic Packaging Technology Conference, pp. 304-309, 1997.

[6] L. Shan, J. Trewhella, C. Baks, R. John, W. Dyckman, D. O'Connor, and E. Pillai, "A low-cost ceramic BGA package for $50 \mathrm{~Gb} / \mathrm{s}$ multiplexing circuit", Electrical Performance of Electronic Packaging, pp. 59-62, 2003.

[7] H. Hasan, A. Cangellaris, R. Kaw, and W. Pinello, "Effects of heat spreader on electrical characteristics of tape-BGA packages", IEEE 6th Topical Meeting on Electrical Performance of Electronic Packaging, pp. 153-156, 1997.

[8] Rinebold, K. and Newberry, W. "Trends in BGA design methodologies", Proceedings of 1998 IEEE Symposium on IC/Package Design Integration, pp. 120-123, 1998.

[9] Ming-Kun Chen and Cheng-Chi Tai, "Electrical characterization of BGA test socket for high-speed applications", Proceedings of the 4th International Symposium on Electronic Materials and Packaging, pp. 123-126, 2002.

[10] Da-Yuan Shih, Paul Lauro, Keith Fogel, Brian Beamanaj, Yun-Hsin Liao, and James Hedrick., "New ball grid array module test sockets", Proceedings of the Electronic Components \& Technology Conference, vol. 46, no. 1, pp. 467470.

[11] Benson Chan, "BGA sockets - A dendritic solution", Proceedings of the Electronic Components \& Technology Conference, vol. 46, no. 1, pp. 460-466, 1996.

[12] H. Koeppen and L. Muller, “Alloys C17400 and C17410-New beryllium copper alloys for connector applications", IEEE Transactions on Components, Hybrids, and Manufacturing Technology, vol. 9, 
Issue 3, pp. 310-316, 1986.

[13] I.J. Zatz and H.A. Murray, "Fracture testing of beryllium copper alloy C17510", Proceedings, 14th IEEE/NPSS Symposium on Fusion Engineering, vol. 1, pp. 276-279, 1991.

[14] 김상원, 조찬섭, 남재우, 김봉환, 이종현, "MEMS 공정을 이용한 BGA IC 패키지용 테 스트 소켓의 제작”, 대한전자공학회 논문지 제47권 SD편, 제11호, pp. 749-753.

[15] Bong-Hwan Kim, Jong-bok Kim, and Jong-Hyun Kim, "A highly manufacturable large area array MEMS probe card using electroplating and flipchip bonding”, IEEE Transactions on Industrial
Electronics, vol. 56, no. 4, pp. 1079-1085, April 2009,

[16] Chanseob Cho, Sangwon Kim, Daeyoung Kong, Jaewoo Nam, Bonghwan Kim, and Jonghyun Lee, "Design and fabrication of highly manufacturable MEMS test sockets for BGA IC packages", Japanese Journal of Applied Physics, vol. 50, no. 6, 06GM17, June 20, 2011.

[17] J. Santander, M. Lozano, A. Collado, M. Ullan, and E. Cabruja, "Accurate contact resistivity extraction on Kelvin structures with upper and lower resistive layers", IEEE Transactions on Electron Devices, vol. 47, Issue 7, pp. 1431-1439, 2000.

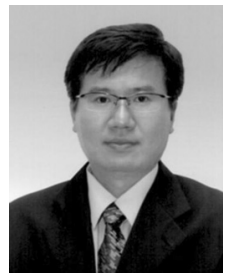

김 봉 환(Bonghwan $\mathrm{Kim})$

- 1996년 경북대학교 전자공학과(공학사)

- 1999년 서울대학교 전기컴퓨터공학부(공 학석사).

- 2005년 서울대학교 전기컴퓨터공학부 (공학박사)

- 2001년 2005년 (주)아이씨멤즈 대표이사

- 2005년 2007년 (주)유니테스트 수석연구원

- 2008년 2009년 Post-doctoral researcher at University of Illinois at UrbanaChampaign

- 2009년 2011년 대구가톨릭대학교 전자 공학과 전임강사.

- 2009년 현재 대구가톨릭대학교 전자공 학과 조교수

- 주관심분야 : $\mathrm{MEMS/NEMS,} \mathrm{반도체공}$ 정, $\mathrm{MEMS}$ actuator, probe card, test socket, solar cell 